\title{
Percepções sobre a violência no bairro do Benguí, Belém, Pará, Brasil, por agentes territoriais de Segurança Pública e Defesa Social
}

\author{
Perceptions about violence in the neighborhood of Benguí, Belém, Pará, Brazil, by territorial agents \\ of Public Security and Social Defense
}

Percepciones sobre la violencia en el barrio de Benguí, Belém, Pará, Brasil, por agentes territoriales de Seguridad Pública y Defensa Social

Isis Kelma Figueiredo de Araújo ORCID: https://orcid.org/0000-0001-6029-8660 Universidade Federal do Pará, Brasil E-mail: isiskelma@gmail.com

Fernando Alberto Souza Lima ORCID: https://orcid.org/0000-0001-7376-339X Universidade Federal do Pará, Brasil E-mail: fernandopmpa@gmail.com Jorge Luiz Aragão Silva ORCID: https://orcid.org/0000-0001-8454-6585 Universidade Federal do Pará, Brasil E-mail: afisicavive@yahoo.com.br

Ricardo André Biloia da Silva ORCID: https://orcid.org/0000-0002-6007-4779 Universidade Federal do Pará, Brasil E-mail: ricardoanndre@gmail.com

Andrea Bittencourt Pires Chaves ORCID: https://orcid.org/0000-0003-0247-9265 Universidade Federal do Pará, Brasil E-mail: andreachaves@ufpa.br

Marcus Alan de Melo Gomes ORCID: https://orcid.org/0000-0002-3699-5164 Universidade Federal do Pará, Brasil E-mail: marcusalan60@hotmail.com

Clay Anderson Nunes Chagas ORCID: http://orcid.org/0000-0002-4223-0192 Universidade Federal do Pará, Brasil E-mail: claychagas@ufpa.br

\begin{abstract}
Resumo
Este artigo tem como objetivo verificar, dentre as correntes teóricas da sociologia que contribuem à compreensão do fenômeno da violência, qual a mais expressiva a partir da percepção dos agentes de segurança pública responsáveis pelo atendimento de ocorrências de casos de violência no Bairro do Benguí, no município de Belém, estado do Pará, Brasil. Trata-se de estudo quantitativo com questionários estruturados, aplicados a policiais militares e bombeiros militares, que atuavam no referido bairro, para caracterizar e compreender o fenômeno da violência. Foram utilizadas nas alternativas princípios de correntes de pensamento sociológico da Teoria Política (Nicolau Maquiavel), do Contratualismo (Thomas Hobbes), do Liberalismo (Adam Smith), do Funcionalismo (Émile Durkheim) e da Sociologia Compreensiva (Max Weber). Como resultado, verificou-se a prevalência de ideias liberalistas, com $42 \%$ geral das respostas. Foi constatado também que a corrente de Adam Smith foi a mais expressiva nos níveis fundamental e médio de escolaridade. A prevalência liberal foi comum entre policiais e bombeiros, exceto quanto à principal causa da violência, em que a maioria dos bombeiros se alinhou à Teoria Política, de Nicolau Maquiavel. Os resultados mostraram correspondência ao pensamento criminológico crítico, sobre a compreensão seletiva das agências de segurança pública quanto à violência e de falha nos mecanismos de controle social no bairro. Concluiu-se com a prevalência do pensamento liberal nas quatro percepções investigadas: principais causas da violência no bairro (35\%); melhores soluções ao fenômeno (47\%); maiores dificuldades para alcançar soluções à violência (42\%) e; razões para o fortalecimento do tráfico de drogas no bairro (45\%).

Palavras-chave: Violência; Agentes territoriais; Segurança pública; Defesa social; Correntes sociológicas; Criminologia crítica.
\end{abstract}




\begin{abstract}
This article aims to verify, among the theoretical currents of sociology that contribute to the understanding of the phenomenon of violence, which is the most expressive from the perception of public security agents responsible for dealing with occurrences of cases of violence in neighborhood of Benguí, in the city of Belém, state of Pará, Brazil. It is a quantitative study with structured questionnaires applied to military police and military firefighters, who worked in the referred neighborhood, to characterize and understand the phenomenon of violence. Alternative principles of sociological thought currents from Political Theory (Nicolau Machiavelli), Contractualism (Thomas Hobbes), Liberalism (Adam Smith), Functionalism (Émile Durkheim) and Comprehensive Sociology (Max Weber) were used in the alternatives. As a result, there was a prevalence of liberalist ideas, with $42 \%$ overall of responses. It was also found that Adam Smith's current was the most expressive at the elementary and middle school levels. Liberal prevalence was common among police and firefighters, except for the main cause of violence, in which the majority of firefighters aligned themselves with Nicolau Machiavelli's Political Theory. The results also showed correspondence to critical criminological thinking, about the selective understanding of public security agencies regarding violence and the failure of social control mechanisms in the neighborhood. It concluded that the liberal thinking was the most prevalent among the four perceptions investigated: a) main causes of violence in the neighborhood (35\%); b) better solutions to the phenomenon (47\%); c) greater difficulties in reaching solutions to violence (42\%) and; d) reasons for strengthening drug trafficking in the neighborhood (45\%).
\end{abstract}

Keywords: Violence; Territorial agents; Public security; Social defense; Sociological currents; Critical criminology.

\title{
Resumen
}

Este artículo tiene como objetivo verificar, entre las corrientes teóricas de la sociología que contribuyen a la comprensión del fenómeno de la violencia, cuál es la más expresiva desde la percepción de los agentes de seguridad pública encargados de atender la ocurrencia de casos de violencia en el Bairro do Benguí, en la ciudad de Belém, estado de Pará, Brasil. Se trata de un estudio cuantitativo con cuestionarios estructurados, aplicado a policías militares y bomberos militares, que laboraban en el referido barrio, para caracterizar y comprender el fenómeno de la violencia. En las alternativas se utilizaron principios alternativos de las corrientes de pensamiento sociológico de la Teoría Política (Nicolau Machiavelli), el Contractualismo (Thomas Hobbes), el Liberalismo (Adam Smith), el Funcionalismo (Émile Durkheim) y la Sociología Integral (Max Weber). Como resultado, prevalecieron las ideas liberalistas, con $42 \%$ en general de respuestas. También se encontró que la corriente de Adam Smith era la más expresiva en los niveles de primaria y secundaria. La prevalencia liberal fue común entre policías y bomberos, excepto por la principal causa de violencia, en la que la mayoría de los bomberos se alinearon con la Teoría Política de Nicolau Machiavelli. Los resultados también encontraron correspondencia con el pensamiento crítico criminológico, sobre la comprensión selectiva de los organismos de seguridad pública sobre la violencia y el fracaso de los mecanismos de control social en el barrio. Se concluyó con la prevalencia del pensamiento liberal en las cuatro percepciones investigadas: a) principales causas de violencia en el barrio (35\%); b) mejores soluciones al fenómeno (47\%); c) mayores dificultades para encontrar soluciones a la violencia $(42 \%)$ y; d) razones para fortalecer el narcotráfico en el barrio (45\%).

Palabras clave: Violencia; Agentes territoriales; Seguridad Pública; Defensa social; Corrientes sociológicas; Criminología crítica.

\section{Introdução}

A Constituição Federal de 1988 estabelece que policiais militares e bombeiros militares são denominados militares estaduais, bem como dispõe que "às polícias militares cabem a polícia ostensiva e a preservação da ordem pública; aos corpos de bombeiros militares, além das atribuições definidas em lei, incumbe a execução de atividades de defesa civil” (Brasil, 1988).

A Polícia Militar (PM) e o Corpo de Bombeiros Militar (CBM) integram o Sistema Estadual de Segurança Pública e Defesa Social, juntamente com a Polícia Civil (PC), Centro de Perícias Científicas "Renato Chaves" (CPC RC), Departamento Estadual de Trânsito (DETRAN) e, Secretaria de Estado de Administração Penitenciária (SEAP) (Pará, 2011).

Em razão das especificidades de suas missões constitucionais, a PM e o CBM apresentam atuação em todo o território do estado do Pará, com atendimento mais desconcentrado e dinâmico à população, para fazer frente aos chamados de emergência, bem como proporcionando que seus agentes estejam em contato direto e frequente com os demais agentes territoriais nos bairros, favorecendo assim que as percepções dos militares estaduais sobre a violência se comuniquem com as percepções de outros agentes territoriais que integram suas rotinas de serviço na área de atuação. 
A pluralidade de discussões envolvendo a violência alcança inúmeras teorias nas diversas áreas do conhecimento apontando fatores responsáveis ou influentes para o resultado em violência. Dentre essas teorias, pode-se destacar alguns expoentes do pensamento sociológico, que discorreram sobre a violência, contribuindo com suas ideias para o alicerçamento de correntes que muitas vezes traduzem a forma como o fenômeno é percebido hoje pelas pessoas na sociedade.

A presente pesquisa surge com o propósito de verificar a influência que essas correntes teóricas sociológicas que abordam o fenômeno da violência exercem na percepção dos agentes de segurança pública, sob a perspectiva da Teoria Política, de Nicolau Maquiavel (1469-1527); do Contratualismo, de Thomas Hobbes (1588-1679); do Liberalismo, de Adam Smith (1723-1790); do Funcionalismo, de Émile Durkheim (1858-1917) e a Sociologia Compreensiva, de Max Weber (18641920).

Os agentes de segurança pública são responsáveis pelo serviço prestado diretamente pelo Estado à sociedade para fazer frente às práticas de violência e criminalidade, sendo, portanto, oportuno questionar: que corrente sociológica exerceria hoje maior influência junto aos agentes de segurança pública em determinado espaço e período?

Assim, esta pesquisa objetiva verificar, dentre as correntes teóricas da sociologia que contribuem à compreensão do fenômeno da violência, qual é a mais expressiva junto aos agentes de segurança pública responsáveis pelo atendimento de ocorrências emergenciais de casos de violência no Bairro do Benguí, no ano de 2019.

\section{Metodologia}

Trata-se de estudo quantitativo, descritivo e exploratório com aplicação de questionário construído especificamente para mensurar a percepção dos militares estaduais que atuam na referida área (policiais e bombeiros militares) sobre a violência no bairro do Benguí, Belém-PA. Para Gil (2017), as pesquisas descritivas buscam levantar opiniões e crenças de determinada população, ao passo que as pesquisas de cunho exploratório levam o pesquisador a observar e compreender o fenômeno sob as mais variadas concepções.

Do universo de militares estaduais que atuavam na área do bairro do Benguí em 2019, foi alcançado o censo de 59 (cinquenta e nove) policiais militares lotados na $1^{\mathrm{a}}$ Companhia do $24^{\circ}$ Batalhão de Polícia Militar e 18 (dezoito) bombeiros militares lotados no $27^{\circ}$ Grupamento de Bombeiros Militares, totalizando 77 (setenta e sete) questionários respondidos.

A pesquisa foi construída a partir de dados primários, coletados pelos autores por questionários junto aos policiais militares e bombeiros militares que trabalham no Benguí, no período de 06 a 20 de junho de 2019. Durante a aplicação, o objetivo foi gerar um espaço de forma que os militares estaduais pudessem transmitir suas percepções sobre a violência, sem interferência de colegas ou superiores hierárquicos.

O questionário foi estruturado em três partes. A primeira parte consta de questões preliminares para identificar o perfil do público alvo, quanto ao sexo, escolaridade, corporação que integra: Polícia Militar ou Corpo de Bombeiros Militar, tempo de serviço na instituição e tempo de serviço no bairro.

A segunda parte do questionário consta de perguntas sobre a caracterização do fenômeno da violência no bairro por esse público, de modo que os entrevistados indicam entendimento sobre a abrangência do termo violência, podendo optar se o conceito se constitui em toda prática de crime, apenas a prática de crimes com agressividade, se é mais abrangente que a prática de crimes, se constitui apenas a prática de alguns crimes ou nenhuma dessas.

Em seguida, identificam-se características dos atendimentos realizados, tais como locais de maior incidência (via pública, residências, estabelecimentos comerciais, escolas, outros); tipos de violências mais percebidas (contra o patrimônio, contra a pessoa, contra a paz pública, contra os costumes ou nenhuma dessas) e sobre as vítimas atendidas e autores identificados (crianças, adolescentes, adultos jovens, adultos, idosos, ou nenhum desses). 
A terceira parte do questionário foi destinada a verificar as percepções sobre a violência no bairro em si, perquirindo sobre qual a principal causa, a melhor solução, a maior dificuldade para resolver o problema e, a principal razão para o crescimento do tráfico de drogas no bairro, sendo que as alternativas propostas foram vinculadas a elementos centrais das cinco teorias sociológicas já apresentadas: Teoria Política, Contratualismo, Liberalismo, Funcionalismo e Sociologia Compreensiva; com o objetivo de verificar qual dessas teorias traduziria melhor as percepções dos sujeitos entrevistados.

\section{Resultados e Discussão}

\subsection{Compreensões Sociológicas da Violência}

Dentre as correntes teóricas que abordam o fenômeno da violência, destacam-se a Teoria Política, de Nicolau Maquiavel (1469-1527); o Contratualismo, de Thomas Hobbes (1588-1679); o Liberalismo, de Adam Smith (1723-1790); o Funcionalismo, de Émile Durkheim (1858-1917) e a Sociologia Compreensiva, de Max Weber (1864-1920).

Para Winter (2006), o pensamento de Nicolau Maquiavel divergiu dos costumes que assinala a predisposição do homem para viver em sociedade de forma natural, assim, de maneira oposta, os homens estariam inclinados à desavença e cisão, emanando, nesse sentido, uma tensão social, assinalada por atrito de dois grupos sociais diferentes.

Neste conflito, tem-se de um lado "o povo", que deseja não ser oprimido pelos grandes, e de outro lado "os grandes" que, inversamente, desejam oprimir e dominar o povo. Dessa forma, o principado deriva, conforme a conjuntura, do povo ou dos que detém o poder (Winter, 2006; Maquiavel, 2011).

O Estado (Príncipe) deve agir com "virtù", ou seja, agir de acordo com as circunstâncias como forma de justificativa para o bem coletivo. Assim, em determinados momentos se admite o uso de ações cruéis contrapondo ações humanitárias, por considerar virtuosas quando beneficiam a coletividade. Por esta razão, há violências que politicamente se justificam quando o fim último for o bem comum (Winter, 2006).

Com isso, a teoria política de Nicolau Maquiavel revela a violência política, que se justifica pelo bem comum da coletividade, de maneira que as ações violentas do Estado se justificam perante a população apenas quando em função do bem comum; do contrário, gera revolta. Assim, outras formas de violência que não tenham o fim de preservar a dicotomia Estado e bem da coletividade devem ser evitadas (Winter, 2006).

Por outro lado, Thomas Hobbes, na obra Leviatã, discorre sobre um estado de guerra de todos contra todos, no sentido que a guerra sempre infere violência. Trata-se de uma visão política no estágio inicial da vida humana, de modo que cada homem é seu próprio soberano (Matos, 2016).

Assim sendo, todos podem matar a todos; todos podem morrer; todos são iguais. Essas vontades individuais devem ser superadas por um ente maior, o Estado, segundo Thomas Hobbes, pois só assim os indivíduos não mais viveriam com medo das violências. Portanto, o único modo de sair deste estado de guerra, ou estado de natureza, seria cada cidadão abrir mão de suas liberdades individuais, colocando-as sob a égide do Estado, que passa a ter, então, controle sobre o modo de viver daquele indivíduo. Isso seria, em síntese, o contrato social que Thomas Hobbes defende. Por conta do pacto, tem-se o que, modernamente se denomina como sociedade civil (Hobbes, 1979).

Para Cabral (2004), a corrente teórica do funcionalismo resulta em diferentes perspectivas, de modo que não subsiste abordagem específica mais importante ou significativa. Um dos principais expoentes dessa corrente é Émile Durkheim e dentre as ideias que fazem parte de sua teoria geral, destaca-se o conceito de "consciência coletiva", significando o conjunto das crenças e sentimentos comuns à média dos membros de uma sociedade que forma um sistema determinado, com vida própria. A consciência coletiva existe em função dos sentimentos e crenças presentes nas consciências individuais, mas não é apenas a expressão ou efeito destas. A consciência coletiva evolui segundo suas próprias leis e tem maior extensão nas sociedades dominadas pela solidariedade mecânica (Cabral, 2004). 
Cabral (2004) expõe que ao elaborar essas noções, Émile Durkheim define que o indivíduo nasce da sociedade e não que a sociedade nasce do indivíduo. Dessa forma, denota-se que a sociologia surge como prioridade do todo sobre as partes, explicando, assim, os elementos pelo todo. Diante dessa concepção, a maior ou menor aderência do indivíduo à consciência coletiva, poderia explicar a opção ou não por condutas violentas em sociedade.

$\mathrm{Na}$ visão de Adam Smith a violência instala a forma de um governo, que se fundamenta na proteção e defesa da propriedade. Dessa forma, "os indivíduos aderem à sociedade civil pela sua utilidade na manutenção da ordem e pela autoridade que se concede a alguns homens, decorrente de sua idade, riqueza, supremacia física ou intelectual" (Figueiredo, 1997, p.8).

Para Max Weber, pode-se dizer que a violência está intimamente relacionada à existência do Estado. Neste contexto, sem violência a figura do Estado desapareceria, imperando assim, em seu lugar, a anarquia. O Estado seria aquele que detém perante a sociedade o monopólio legítimo para o uso da força, portanto, afirma-se que o Estado é uma relação em que homens dominam seus iguais, por meio da violência legítima, de modo que dominados se sujeitam à autoridade de dominadores (Weber, 1984).

Essa dominação subsiste por três justificativas: a primeira decorre do poder tradicional, ou seja, exercido pela prática dos costumes e hábitos; a segunda, pelo poder carismático com fundamento na autoridade por dons pessoais e extraordinários daquele que possui qualidades ou heroísmo que o fazem chefe; a terceira, impõe-se em razão da legalidade fundada na obediência às regras racionalmente estabelecidas. (Weber, 1984).

\subsection{Criminologia crítica e Segurança Pública}

Segundo Zaffaroni (2017), a atuação racional das agências que integram o sistema penal, dentre as quais aqui se destacam as agências policiais e os sistemas de segurança pública ao lado do Judiciário e sistema penitenciário, condicionam a legitimidade do poder social manifestado por meio do sistema penal.

O sistema penal pode ser compreendido por três dimensões que se expressam pela dogmática jurídico-penal, a política criminal e a criminologia. O saber da ciência penal é dado pela dogmática jurídico-penal, que estabelece critérios para compreensão do fenômeno criminal e sua interpretação legal (Aguiar, 2016).

Já o conjunto de estratégias e mecanismos de controle social que vão desde o processo de elaboração das normas penais (processo legislativo) e das ações concretas das agências executivas, sobretudo das polícias e dos órgãos de justiça, compreendem a política criminal (Aguiar, 2016).

A criminologia, segundo Castro (2015), vem ao longo do tempo, ocupando-se do estudo do delito, do delinquente, da delinquência e dos processos de criminalização. São por esses processos que as agências policial e judicial selecionam um reduzido número de pessoas que submetem à sua coação com o fim de impor-lhes uma pena, em regra privativa de liberdade (Zaffaroni et al., 2011, p. 43).

Dentro da corrente da criminologia crítica, Zaffaroni et al. (2011) assevera que a experiência latinoamericana demonstra a incapacidade das agências do sistema penal (onde se encontram os agentes de segurança pública) em resolver problemas cotidianos da população gerados pela poluição (como o lixo e a perturbação do sossego), práticas de colarinho branco, trânsito, econômicos, entre outras manifestações locais de violência. Tal compreensão levaria à ênfase no enfrentamento aos delitos patrimoniais e seus reflexos.

Essa compreensão traduz um pressuposto da criminologia crítica de que o sistema penal atua de forma seletiva, elegendo condutas a serem criminalizadas, tipos penais a serem reprimidos e sujeitos a serem punidos. Assim, nem todas as condutas desvaloradas serão criminalizadas, nem todas as condutas criminalizadas serão reprimidas pelas instâncias policiais, e nem todos os agentes de comportamentos ilícitos serão punidos pelas instâncias judiciais, pois o sistema penal se faz seletivo. 
Outro pressuposto da criminologia crítica diz respeito à falha no controle social, segundo o qual a religião, a ética, os usos e costumes, o direito, etc, constituem um conjunto de regras de conduta que estabelece o controle social segundo uma lógica de contenção para garantir "a fidelidade ou, no fracasso dela, a submissão" das massas aos valores do sistema dominante (Castro, 2015, p.53).

Nesse sentido, a escola, a igreja, os meios de comunicação e, em particular, as agências que integram o sistema de segurança pública, exercem um importante papel na adequação das condutas dos agentes territoriais ao consenso instituído pela política criminal. Assim, o exame da percepção dos agentes territoriais de segurança pública sobre a violência no bairro perpassa pela compreensão do papel por eles exercido dentro do sistema de controle social.

\subsection{O Bairro do Benguí}

O bairro do Benguí, localizado na capital paraense, começou a se constituir, de forma desordenada, em meados da década de 1940, pela migração interna dos moradores de outros bairros e municípios de Belém. Por estar localizado em área periférica da cidade, atraiu pessoas de baixa e média renda, inicialmente (Lamarão; Maciel, 2006; Amorim et al, 2013).

Sua população, que é de aproximadamente 29.379 habitantes, dos quais 52,29\% são mulheres e 47,71\%, homens (Ibge, 2010), ainda hoje é composta por pessoas de baixa e média renda, que representam 2,1\% da população total de Belém (Ibge, 2010).

De acordo com o Art. $1^{\circ}$ da Lei n ${ }^{\circ} 7.806 / 96$, possui a seguinte delimitação territorial:

Compreende a área envolvida pela poligonal que tem início na interseção da Estrada da Pratinha com a Estrada do Yamada segue por esta até encontrar com a Estrada do Benguí, dobra à esquerda e segue por esta até encontrar o muro da CATA, que faz fundo com a Pass. S. José e segue por esta até encontrar a Pass. S. Francisco, segue por esta até a Pass. S. Benedito, segue por esta até a Pass. Santo Antonio, flete à esquerda e segue por esta até a projeção do travessão do Residencial Natália Lins, dobra à direita e segue por este até encontrar a Pass. Magalhães Barata, flete à direita e segue por esta até encontrar os limites do terreno do muro da INFRAERO por onde segue até encontrar a lateral esquerda do Cemitério do Benguí $(9.848 .150 \mathrm{mN} / 781.800 \mathrm{mE})$, flete à direita e segue por esta até encontrar o travessão dos terrenos da MICON $(9.848 .160 \mathrm{mN} / 782060 \mathrm{mE})$, dobra à esquerda e segue por este até encontrar a Estrada da Pratinha $(9.848 .380 \mathrm{mN} / 782060 \mathrm{mE})$, dobra à direita e segue por esta até a Estrada S. Clemente, dobra à direita e segue por esta até sua interseção com Igarapé Val-de-Cães por onde segue a montante até a Estrada da Pratinha, flete a direita e segue por esta até o início da poligonal (Belém, 1996).

Com área total de $1,9729 \mathrm{~km}^{2}$ e 6.137 domicílios particulares, somente 4.063 são regularmente abastecidos pela rede pública de fornecimento de água; 226 não possuem banheiros ou sanitários; 3.543 dispõem de fossa séptica e 5.949 têm coleta regular de lixo domiciliar. Realidade reflete outro indicador do Instituto Brasileiro de Geografia e Estatística (IBGE), que desde 1991 analisa a presença de aglomerados subnormais nas áreas de estudo (Ibge, 2010).

Segundo o IBGE, os aglomerados subnormais correspondem a:

Um conjunto constituído de, no mínimo, 51 unidades habitacionais (barracos, casas etc.) carentes, em sua maioria de serviços públicos essenciais, ocupando ou tendo ocupado, até período recente, terreno de propriedade alheia (pública ou particular) e estando dispostas, em geral, de forma desordenada e densa. A identificação dos aglomerados subnormais deve ser feita com base nos seguintes critérios: a) Ocupação ilegal da terra, ou seja, construção em terrenos de propriedade alheia (pública ou particular) no momento atual ou em período recente (obtenção do título de propriedade do terreno há 10 anos ou menos); e b) Possuírem pelo menos uma das seguintes características: urbanização fora dos padrões vigentes - refletido por vias de circulação estreitas e de alinhamento irregular, lotes de tamanhos e formas desiguais e construções não regularizadas por órgãos públicos; ou precariedade de serviços públicos essenciais (Ibge, 2010). 
O Benguí apresenta aproximadamente $75 \%$ de sua área com aglomerados subnormais que, segundo Borges et al. (2016), traduzem o contexto sobre as desigualdades no país, especialmente relacionadas à habitação, conforme a Figura 1 (Ibge, 2010):

Figura 1. Mapa de localização do bairro do Benguí, 2020.

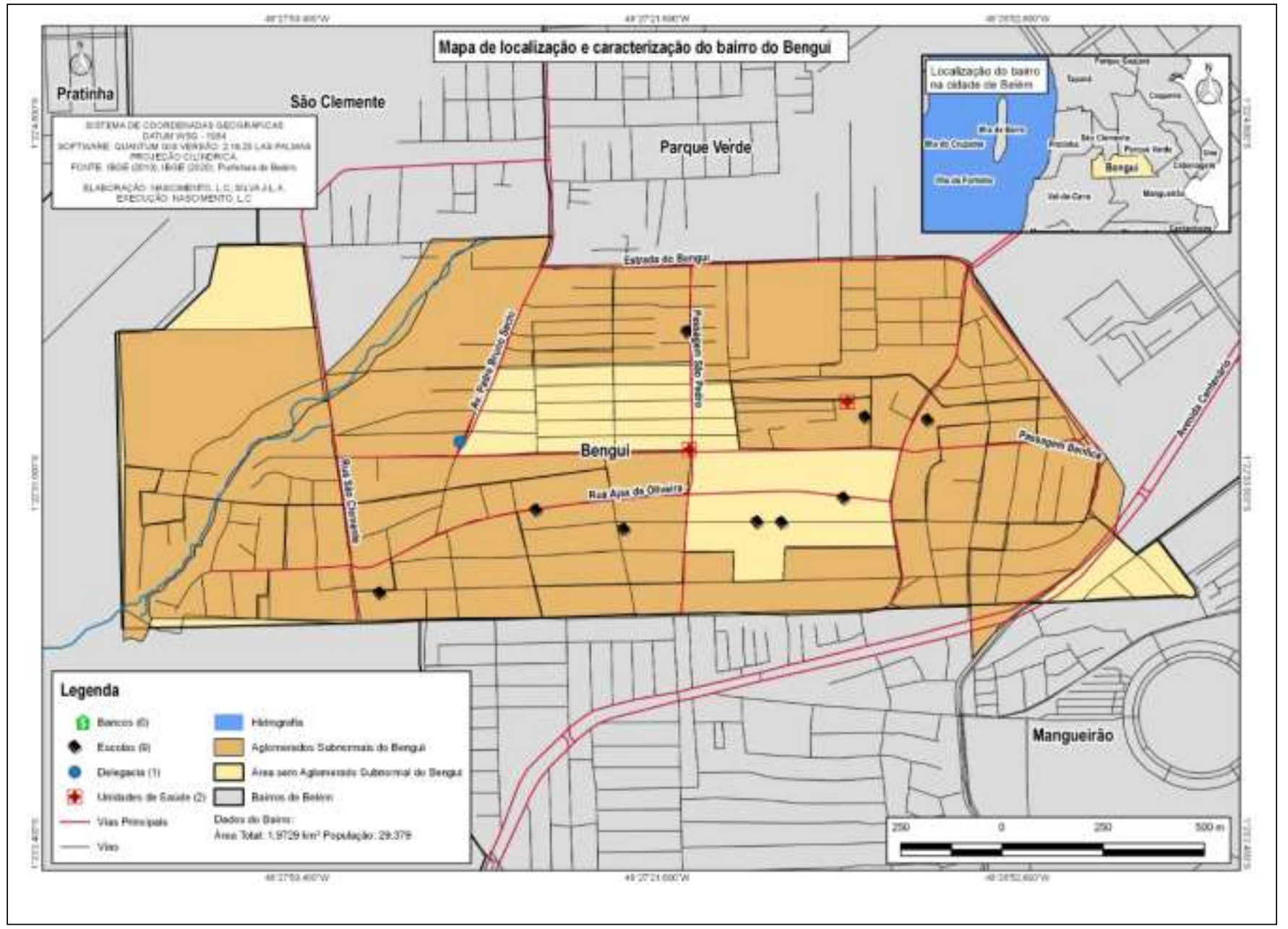

Fonte: Diretoria de Prevenção da Secretaria de Segurança Pública e Defesa Social do Pará (2020).

O bairro foi escolhido para a pesquisa de percepção da violência por militares do sistema de segurança pública, por ter figurado no ano de 2018, na posição mediana da relação dos bairros de Belém quanto aos registros de ocorrências policiais sobre criminalidade violenta (Pará, 2019). Em uma série de dados ordenada, a Mediana representa a posição central, sendo que as medidas de tendência central têm a propriedade estatística de melhor representar o conjunto de dados, expressando o comportamento mais equidistante dos comportamentos extremos de um universo em análise. 
Tabela 1. Número total de registros de ocorrências policiais relacionadas com a criminalidade violenta, por bairros de BelémPA no ano de 2018.

\begin{tabular}{|c|c|c|}
\hline Ordem & Bairro & Registros de ocorrências \\
\hline 1 & Marco & 6302 \\
\hline 2 & Guamá & 5675 \\
\hline 3 & Pedreira & 4752 \\
\hline 4 & Jurunas & 4690 \\
\hline 5 & São Brás & 4583 \\
\hline 6 & Campina; & 4141 \\
\hline 7 & Marambaia & 3817 \\
\hline 8 & Castanheira & 3063 \\
\hline 9 & Umarizal & 3056 \\
\hline 10 & Sacramenta & 3054 \\
\hline 11 & Parque Verde & 2973 \\
\hline 12 & Telégrafo Sem Fio & 2649 \\
\hline 13 & Nazaré & 2646 \\
\hline 14 & Batista Campos & 2558 \\
\hline 15 & Mangueirão & 2507 \\
\hline 16 & Terra Firme & 2347 \\
\hline 17 & Cidade Velha & 2315 \\
\hline 18 & Benguí & 2073 \\
\hline 19 & Cremação & 2036 \\
\hline 20 & Coqueiro Belém & 1943 \\
\hline 21 & Condor & 1930 \\
\hline 22 & Reduto & 1381 \\
\hline 23 & Cabanagem & 1295 \\
\hline 24 & Val-de-Cans & 1086 \\
\hline 25 & Maracangalha & 1023 \\
\hline 26 & Canudos & 967 \\
\hline 27 & Souza & 754 \\
\hline 28 & Barreiro & 738 \\
\hline 29 & Curió-Utinga & 712 \\
\hline 30 & Fátima & 656 \\
\hline 31 & Uma & 459 \\
\hline 32 & Ilhas do Arquipélago do Rio Guamá & 20 \\
\hline 33 & Miramar & 17 \\
\hline 34 & Universitário & 9 \\
\hline 35 & Infraero & 6 \\
\hline \multirow[t]{2}{*}{36} & Ilha do Cumbú & 5 \\
\hline & Total Geral & 78238 \\
\hline
\end{tabular}

Fonte: Secretaria de Segurança Pública e Defesa Social do Pará (2019).

Além disso, o bairro do Benguí foi eleito ao lado da Cabanagem, Guamá, Jurunas, Terra Firme, Icuí Guajará e São João, como bairros da região metropolitana para sediar a primeira fase do programa do governo estadual denominado Territórios pela Paz, que tem por objetivo a diminuição da vulnerabilidade social e o enfrentamento das dinâmicas da violência, a partir da articulação de ações de segurança pública e ações de cidadania (Pará, 2019b).

\subsection{Perfil dos Entrevistados}

Dos 77 (setenta e sete) questionários aplicados, 59 (cinquenta e nove) foram respondidos por policiais militares, que representam o universo lotado na $1^{\mathrm{a}}$ Companhia do $24^{\circ}$ Batalhão de Polícia Militar e, 18 (dezoito) foram respondidos por bombeiros militares, que representam o universo do $27^{\circ}$ Grupamento de Bombeiros Militares. 
3.4.1. Quanto ao sexo, $94 \%$ são do sexo masculino tanto para os policiais militares, quanto para os bombeiros militares e, $6 \%$ são do sexo feminino.

3.4.2. Quanto à escolaridade, em relação ao efetivo geral: 67\% possui Ensino Médio; 30\% possui Ensino Superior e; 3\% possui Ensino Fundamental.

3.4.3. Quanto ao tempo de serviço na Corporação, $44 \%$ desse efetivo possui acima de 20 anos de serviço em suas corporações; $25 \%$ possui entre 10 e 20 anos, $18 \%$ possui entre 5 e 10 anos e, $13 \%$ possui até 5 anos de serviço.

3.4.4. Quanto ao tempo de serviço no bairro do Benguí, contabilizou-se que $66 \%$ desse efetivo possui até 5 anos de serviço no Bairro, 23\% possui entre 5 e 10 anos, $6 \%$ entre 10 e 15 anos, $4 \%$ acima de 15 anos.

\subsection{Caracterização da Violência no Benguí}

3.5.1. Quanto à abrangência do termo "violência": mais da metade dos militares (58\%) expressaram que consideram "toda a prática de crime como um ato de violência". O segundo entendimento mais recorrente foi o de que "a prática de violência é mais abrangente que a prática de crimes" (22\%). Já o entendimento de que "a prática de violência compreende apenas a prática de alguns crimes" representou a terceira percepção mais apontada (9\%).

Esse resultado sinaliza para a percepção por parte da maioria desses agentes de segurança pública da violência por meio dos delitos penais. Tal entendimento pode obstar a percepção de outras manifestações de violência presentes no dia a dia da atividade desses agentes, tal como a violência psicológica contra a mulher, prevista na Lei 11.340, de 07 de agosto de 2006 (Brasil, 2006).

Ainda quanto à abrangência da compreensão sobre a violência, tal entendimento reforça o que a criminologia crítica vem afirmando (Zaffaroni, 2017), de que as agências do sistema penal (onde se encontram os agentes de segurança pública), demonstram incapacidade (ou falta de direcionamento) para resolver outros problemas cotidianos da população, que podem ser mais significativos em termos de efeito à coletividade, tais como a poluição, práticas de colarinho branco, trânsito, econômicos, entre outros.

3.5.2. Quanto ao local de maior incidência: $80 \%$ dos militares expressaram que a "via pública" é o local que ocorre a maior incidência da prática de violência no bairro. A segunda percepção desse público foi que o local é nas residências (12\%).

Dentre as várias possibilidades de interpretação, esse achado aponta para a necessidade de aprimoramento constante das estratégias de pronta resposta diante dos problemas que a mobilidade urbana nos impõe, bem como a necessidade de aprimoramento dos mecanismos de prevenção da violência doméstica.

3.5.3. Quanto aos principais tipos de violência: $45 \%$ dos militares expressaram que os "crimes contra a pessoa" são a maior forma de expressão da violência no bairro, seguidos pelos “crimes patrimoniais" (36\%), sendo que essa percepção se mostra muito equilibrada entre os policiais militares, com sutil vantagem dos crimes patrimoniais. Já os bombeiros evidenciam os crimes contra a pessoa como principal. Tal diferença deve ocorrer em razão da natureza dos atendimentos, visto que os bombeiros atendem as pessoas vítimas de lesões físicas e os policias militares atendem vítimas de todos os delitos, sendo os crimes patrimoniais (roubo e furto) os primeiros colocados nas estatísticas oficiais (Pará, 2019).

Uma das implicações desse resultado diz respeito a necessidade de investimento em mecanismos de resolução pacífica de conflitos interpessoais, bem como a reflexão sobre alternativas de geração de emprego e renda.

3.5.4. Vítimas: Sobre as vítimas, $73 \%$ dos militares apontaram os jovens adultos ( 18 a 30 anos incompletos) como as vítimas mais frequentes da violência no bairro, seguidos pelos adolescentes (12 a 18 anos incompletos) (16\%). Os adultos (30 a 60 anos incompletos) apareceram na terceira posição (9\%).

Essa evidência aponta para a necessidade de estratégias de prevenção da violência junto às camadas mais jovens da população, corroborando com as conclusões de Vilaça (2016) que, ao estudar os perfis socioeconômico e criminal das vítimas 
de homicídio na Região Metropolitana de Belém, de 2011 a 2013, verificou que a idade média das vítimas de homicídios com antecedentes criminais, cujas mortes foram registradas no município de Belém é de 28 anos, e considerando o desvio padrão, 68,26\% das vítimas de homicídios possuíam idade entre 20 e 36 anos, sendo 22 anos a idade mais observada.

3.5.5. Autores: Sobre os autores, $61 \%$ dos militares apontaram os jovens adultos ( 18 a 30 anos incompletos) como sendo os autores mais frequentes da violência no bairro, seguidos pelos adolescentes (29\%). Os adultos (30 a 60 anos incompletos) apareceram na terceira posição quanto à percepção sobre autores (8\%). Verifica-se que as percepções quanto às faixas-etárias de autores e vítimas demonstraram resultados similares.

Esse resultado aponta para a necessidade de estratégias de fortalecimento das redes de proteção das camadas mais jovens da população a fim de prevenir situações de risco que favoreçam a iniciação em práticas delituosas.

\subsection{Compreensões da Violência no Benguí}

3.6.1. Principal causa: A respeito da principal causa para a violência no Bairro, $35 \%$ dos militares responderam que ela é "reflexo da falta de investimento na educação", pensamento ilustrativo da corrente teórica de Adam Smith, o Liberalismo. A segunda alternativa mais escolhida, com $23 \%$ foi o "enfraquecimento de valores morais na atualidade", do pensamento teórico de Max Weber, representante da Sociologia Compreensiva. Em terceiro, ficou "a má gestão política que retira alternativas e esperanças ao povo”, pensamento que ilustra a corrente da Teoria Política, tendo por expoente Nicolau Maquiavel.

Tabela 2. Principal causa da violência no bairro do Benguí, Belém-PA, em junho/2019, segundo militares estaduais que atuam na área, conforme pensador e corrente teórica.

\begin{tabular}{lcccc}
\hline \multicolumn{1}{c}{\begin{tabular}{c}
\multicolumn{1}{c}{ Pensadores / } \\
Corrente Teórica
\end{tabular}} & $\begin{array}{c}\text { Quant. } \\
\text { Bombeiros }\end{array}$ & $\begin{array}{c}\text { Quant. } \\
\text { Policiais }\end{array}$ & $\begin{array}{c}\text { Quant. } \\
\text { Total }\end{array}$ & $\begin{array}{c}\text { Percentual } \\
\text { Total }\end{array}$ \\
\hline $\begin{array}{l}\text { Adam Smith } \\
\text { (Liberalismo) }\end{array}$ & 2 & 25 & 27 & $35 \%$ \\
$\begin{array}{l}\text { Max Weber } \\
\text { (Sociologia Compreensiva) }\end{array}$ & 5 & 13 & 18 & $23 \%$ \\
$\begin{array}{l}\text { Émile Durkheim } \\
\text { (Funcionalismo) }\end{array}$ & 1 & 7 & 8 & $10 \%$ \\
$\begin{array}{l}\text { Nicolau Maquiavel } \\
\text { (Teoria Política) }\end{array}$ & 8 & 6 & 14 & $18 \%$ \\
$\begin{array}{l}\text { Thomas Hobbes } \\
\text { (Contratualismo) }\end{array}$ & 2 & 4 & 6 & $8 \%$ \\
$\begin{array}{l}\text { Nenhuma das Respostas Anteriores } \\
\text { Sem Resposta }\end{array}$ & - & 2 & 2 & $3 \%$ \\
\hline Total Geral & - & 2 & 2 & $3 \%$ \\
\hline
\end{tabular}

Fonte: Dados obtidos pelos autores (2019).

Esses dados mostram uma compreensão pela necessidade de investimentos nas escolas do bairro, enquanto mecanismo de difusão das regras de convívio social.

3.6.2. Melhor solução: A respeito da melhor solução para a violência no Bairro, $47 \%$ das respostas foram "melhorar a educação, segurança e justiça", pensamento ilustrativo do Liberalismo. A segunda alternativa mais escolhida, com $17 \%$ foi "trabalhar valores morais na sociedade", que ilustra o pensamento teórico da Sociologia Compreensiva. Duas alternativas empataram na terceira posição, a primeira: "acabar com a impunidade, pois a falta de punição aumenta a violência", pensamento representativo da corrente teórica do Funcionalismo; a outra foi "Fortalecer o papel das instituições que exercem o controle social: Família, Igreja, Estado", pensamento que ilustra a corrente do Contratualismo. 
Tabela 3. Melhor solução para a violência no bairro do Benguí, Belém-PA, em junho/2019, segundo militares estaduais que atuam na área, conforme pensador e corrente teórica.

\begin{tabular}{lcccc}
\hline \multicolumn{1}{c}{\begin{tabular}{c}
\multicolumn{1}{c}{ Pensadores / } \\
Corrente Teórica
\end{tabular}} & $\begin{array}{c}\text { Quant. } \\
\text { Bombeiros }\end{array}$ & $\begin{array}{c}\text { Quant. } \\
\text { Policiais }\end{array}$ & $\begin{array}{c}\text { Quant. } \\
\text { Total }\end{array}$ & $\begin{array}{c}\text { Percentual } \\
\text { Total }\end{array}$ \\
\hline $\begin{array}{l}\text { Adam Smith } \\
\text { (Liberalismo) }\end{array}$ & 9 & 27 & 36 & $47 \%$ \\
$\begin{array}{l}\text { Max Weber } \\
\text { Sociologia Compreensiva) }\end{array}$ & 5 & 8 & 13 & $17 \%$ \\
$\begin{array}{l}\text { Émile Durkheim } \\
\text { (Funcionalismo) }\end{array}$ & - & 10 & 10 & $13 \%$ \\
$\begin{array}{l}\text { Nicolau Maquiavel } \\
\text { (Teoria Política) }\end{array}$ & 2 & 5 & 7 & $9 \%$ \\
$\begin{array}{l}\text { Thomas Hobbes } \\
\text { (Contratualismo) } \\
\text { Nenhuma das Respostas Anteriores }\end{array}$ & 2 & 8 & 10 & $13 \%$ \\
\hline Total Geral & - & 1 & 1 & $1 \%$ \\
\hline
\end{tabular}

Fonte: Dados obtidos pelos autores (2019).

Segundo os entrevistados, a solução ao problema da violência no bairro está relacionada a maiores investimentos nos serviços que garantam a proteção do direito à propriedade, materializados pela segurança e justiça que impõe o cumprimento das normas e, a educação, que ensina esse cumprimento.

4.6.3. Maior dificuldade: Nessa questão, $42 \%$ dos militares responderam que consiste na Falta de qualidade nos serviços públicos, pensamento ilustrativo da corrente teórica do Liberalismo. Com $29 \%$ ficou O enfraquecimento dos valores coletivos, do bem comum, pela falta de punições, pensamento do Funcionalismo. Em terceiro lugar, ficou que as pessoas hoje estão muito propensas a buscar resolver seus problemas ou conflitos a qualquer custo, desrespeitando as normas, partindo da ideia de que os fins justificam os meios, pensamento que ilustra bem o pensamento teórico da Sociologia Compreensiva.

Tabela 4. Maior dificuldade para resolver a violência no bairro do Benguí, Belém-PA, segundo militares estaduais que atuam na área, conforme pensador e corrente teórica, 2019.

\begin{tabular}{lcccc}
\hline \multicolumn{1}{c}{\begin{tabular}{c}
\multicolumn{1}{c}{ Pensadores / } \\
Corrente Teórica
\end{tabular}} & $\begin{array}{c}\text { Quant. } \\
\text { Bombeiros }\end{array}$ & $\begin{array}{c}\text { Quant. } \\
\text { Policiais }\end{array}$ & $\begin{array}{c}\text { Quant. } \\
\text { Total }\end{array}$ & $\begin{array}{c}\text { Percentual } \\
\text { Total }\end{array}$ \\
\hline $\begin{array}{l}\text { Adam Smith } \\
\text { (Liberalismo) }\end{array}$ & 6 & 26 & 32 & $42 \%$ \\
$\begin{array}{l}\text { Max Weber } \\
\text { (Sociologia Compreensiva) }\end{array}$ & 6 & 8 & 14 & $19 \%$ \\
$\begin{array}{l}\text { Émile Durkheim } \\
\text { (Funcionalismo) }\end{array}$ & 2 & 20 & 22 & $29 \%$ \\
$\begin{array}{l}\text { Nicolau Maquiavel } \\
\text { (Teoria Política) }\end{array}$ & 2 & 2 & 5 & $6 \%$ \\
$\begin{array}{l}\text { Thomas Hobbes } \\
\text { (Contratualismo) }\end{array}$ & 3 & - & 1 & $1 \%$ \\
Nenhuma das Respostas Anteriores & 1 & 3 & 3 & $4 \%$ \\
\hline \multicolumn{1}{c}{ Total Geral } & $\mathbf{1 8}$ & $\mathbf{5 9}$ & $\mathbf{7 7}$ & - \\
\hline
\end{tabular}

Fonte: Dados obtidos pelos autores (2019).

Alinhando-se aqui ao Liberalismo, os agentes de segurança reforçam a teoria que defende a eficiência dos serviços públicos, como garantia de usufruto dos direitos à propriedade, sem o que toda a sociedade corre risco.

3.6.4. Tráfico de drogas: A respeito do fortalecimento do tráfico de drogas no bairro, $45 \%$ dos militares responderam que a principal razão consiste na "precariedade dos serviços públicos como educação, saúde, segurança pública”, pensamento 
ilustrativo da corrente teórica representada por Adam Smith, o Liberalismo. A segunda alternativa mais escolhida, com 26\% foi que "muitas pessoas têm em si a compreensão que as drogas (consumo ou comércio) podem ser uma alternativa viável para resolver seus problemas, mesmo que isso contrarie normas sociais", pensamento que ilustra bem o pensamento teórico de Max Weber, representante da Sociologia Compreensiva. A terceira alternativa mais escolhida foi "a falta de atenção dos governantes por meio de políticas públicas especificas e efetivas voltadas para o problema", pensamento que ilustra a corrente da Teoria Política, tendo por expoente Nicolau Maquiavel.

Tabela 5. Principais razões para fortalecimento do tráfico de drogas no bairro do Benguí, Belém-PA, em 2019, segundo militares estaduais que atuam na área, conforme pensadores e correntes teóricas.

\begin{tabular}{|c|c|c|c|c|}
\hline $\begin{array}{c}\text { Pensadores / } \\
\text { Corrente Teórica }\end{array}$ & $\begin{array}{c}\text { Quant. } \\
\text { Bombeiros }\end{array}$ & $\begin{array}{c}\text { Quant. } \\
\text { Policiais }\end{array}$ & $\begin{array}{l}\text { Quant. } \\
\text { Total }\end{array}$ & $\begin{array}{c}\text { Percentual } \\
\text { Total }\end{array}$ \\
\hline $\begin{array}{l}\text { Adam Smith } \\
\text { (Liberalismo) }\end{array}$ & 12 & 23 & 35 & $45 \%$ \\
\hline $\begin{array}{l}\text { Max Weber } \\
\text { (Sociologia Compreensiva) }\end{array}$ & 2 & 18 & 20 & $26 \%$ \\
\hline $\begin{array}{l}\text { Émile Durkheim } \\
\text { (Funcionalismo) }\end{array}$ & 1 & 2 & 3 & $4 \%$ \\
\hline $\begin{array}{l}\text { Nicolau Maquiavel } \\
\text { (Teoria Política) }\end{array}$ & 2 & 9 & 11 & $14 \%$ \\
\hline $\begin{array}{l}\text { Thomas Hobbes } \\
\text { (Contratualismo) }\end{array}$ & 1 & 6 & 7 & $9 \%$ \\
\hline Nenhuma das Respostas Anteriores & - & 1 & 1 & $1 \%$ \\
\hline Total Geral & 18 & 59 & 77 & - \\
\hline
\end{tabular}

Fonte: Dados obtidos pelos autores (2019).

Ainda na linha da defesa da eficiência dos serviços públicos, os agentes de segurança depositam suas expectativas na melhoria dos instrumentos de garantia de direitos para fazer frente ao problema das drogas.

\section{Considerações Finais}

A metodologia empregada nesta pesquisa possibilitou a verificação de que policiais e bombeiros militares que atuavam no bairro do Benguí, em junho de 2019, se mostraram expostos a diferentes percepções de violência no bairro, que traduzem correntes clássicas do pensamento sociológico.

A partir da aplicação do questionário estruturado em questões sobre a violência local, verificou-se que nas percepções sobre essa violência, no geral, a maioria dos militares estaduais entrevistados (42\%) que realizam atendimentos emergenciais no bairro se alinhou ao Liberalismo de Adam Smith. Em segundo lugar, o pensamento mais recorrente foi o da Sociologia Compreensiva de Max Weber (21\%).

A prevalência do pensamento liberal foi verificada nas quatro percepções investigadas, relacionadas: às principais causas da violência no bairro (35\%), às melhores soluções ao fenômeno (47\%), às maiores dificuldades para alcançar soluções à violência (42\%) e, quanto às razões para o fortalecimento do tráfico de drogas no bairro (45\%).

O pensamento de Adam Smith se mostrou mais expressivo nos níveis fundamental e médio de escolaridade, enquanto que, no nível superior em particular, foi evidenciado um equilíbrio dos pensamentos de Max Weber e Nicolau Maquiavel. A prevalência do Liberalismo se mostrou comum tanto entre policiais como entre bombeiros, exceto quanto à principal causa da violência no bairro, de modo que a maioria dos bombeiros se alinhou ao pensamento da Teoria Política de Nicolau Maquiavel (44\%). 
Para compreender o resultado, é necessário também compreender os sujeitos da pesquisa e o território de atuação. Um dos fatores que pode explicar a prevalência do pensamento liberal entre policiais e bombeiros militares no bairro do Benguí, são as crenças institucionais dos órgãos de segurança pública dos órgãos aos quais pertencem, sobre a necessidade de fortalecimento dos mecanismos de proteção ao direito de propriedade para fazer frente à violência, uma vez que os próprios agentes integram órgãos que promovem essa proteção no território de atuação.

Ainda quanto aos sujeitos, outro aspecto importante é quanto ao perfil socioprofissional dos entrevistados, que pode refletir em sua forma de perceber o problema da violência. Nesse sentido, considerando que $94 \%$ são do sexo masculino, as características biológicas e culturais masculinas podem diferir das respostas femininas; assim como sendo 67\% dos entrevistados com até o ensino médio, podendo expressar uma percepção distinta quanto aos agentes com nível superior.

Da mesma forma, $44 \%$ dos agentes com mais de 20 anos de serviço em suas corporações caracterizam um público com grande vivência do serviço e que vem passando por vários contextos socioeconômicos e culturais, adequando-se a novas crenças ou mantendo as antigas. Também os $66 \%$ desse público possuindo até 5 anos de serviço no Bairro mostra uma experiência profissional relativamente recente no território do Benguí.

Outro aspecto importante sobre as percepções dos agentes de segurança sobre a violência do bairro são as condições infraestruturais locais, onde o Benguí possui um elevado percentual de sua área constituída por aglomerados subnormais (75\%), o que expressa uma considerável precariedade das condições de qualidade de vida da população.

Também cabe destacar que a prevalência da corrente liberal sobre a violência no bairro pode corroborar com o pensamento criminológico crítico, segundo o qual as agências do sistema de segurança pública (sistema penal) tendem a selecionar condutas relacionadas aos direitos patrimoniais em detrimento de outros.

A influência dessas características socioprofissionais, territoriais e criminológicas podem ser objeto de futuros aprofundamentos, servindo neste momento para dar suporte a duas conclusões principais desta pesquisa.

A primeira diz respeito sobre a importância do desenvolvimento e aplicação de metodologias, no âmbito da segurança pública do Pará, para analisar a relação entre as percepções de atores locais com correntes do pensamento sociológico, o que pode sinalizar para oportunidades de aprimoramento dos processos de formação inicial e continuada nos órgãos integrantes do sistema de segurança pública, proporcionando maior reflexão junto aos agentes.

A segunda diz respeito à demonstração de que as compreensões aqui verificadas representam um registro da compreensão sociológica sobre a violência, por parte dos agentes de segurança pública, policiais e bombeiros militares, que atendem chamados emergenciais no bairro do Benguí, em 2019.

Por fim, para trabalhos futuros, sugere-se sistematizar o acompanhamento da evolução das compreensões sociológicas dos agentes de segurança pública, proporcionando comparações entre as grandes regiões do estado, relacionando-as com os principais indicadores de situações problema enfrentadas nesses territórios, no âmbito da segurança pública. Verificou-se também a necessidade de comparar as percepções dos agentes de segurança com outros segmentos sociais, como as comunidades escolares, por exemplo, possibilitando maior compreensão e aproximação para trabalhos conjuntos.

\section{Referências}

Amorim, C. R. T. C., Albim, L. B., Cruz, A. L. O., \& Oliveira, J. V. S. (2013). O Bengola: uma voz de resistência em defesa da cidadania na Amazônia. Artigo apresentado no XII Congresso de Ciências da Comunicação na Região Norte, 5p. Manaus-AM, Brasil.

Aguiar, L. (2016). Dogmática Jurídico-Penal, Política Criminal e Criminologia. https://leonardoaaaguiar.jusbrasil.com.br/artigos/ 324816043/ dogmaticajuridico-penal-politica-criminal-e-criminologia.

Belém. Poder Municipal. (1996). Lei n 7.806 de 30 de julho de 1996. Delimita as áreas que compõem os bairros de Belém, revoga a lei no 7.245/84, e dá outras providências.

Borges, R. H. M., Nascimento, R. P. B., Vieira, D. C. M., \& Andrade, L. C. M. (2017). Território, violência e criminalidade: uma análise geográfica sobre os índices de homicídios no bairro do Paar em Ananindeua-Pa. In: Cardozo, E. L (Org). A Sociedade e o Espaço Geográfico Brasileiro. Curitiba: Atena. 
Research, Society and Development, v. 10, n. 1, e56110112201, 2021

(CC BY 4.0) | ISSN 2525-3409 | DOI: http://dx.doi.org/10.33448/rsd-v10i1.12201

Brasil. Governo Federal. (1988). Constituição da República Federativa do Brasil. Brasília, Senado Federal.

Brasil. Governo Federal. (2006). Lei 11.340, de 07 de agosto de 2006. Cria mecanismos para coibir a violência doméstica e familiar contra a mulher (...); e dá outras providências. Brasil. http://www.planalto.gov.br/ccivil_03/_ato2004-2006/2006/lei/111340. htm.

Cabral, A. (2004). A sociologia funcionalista nos estudos organizacionais: foco em Durkheim. Cadernos EBAPE.BR, 2(2), 1-15. http://www.scielo.br/scielo.php?pid=S1679-39512004000200002\&script=sci_arttext.

Castro, L. A. (2015). Criminologia da Libertação (v.10). Revan.

Figueiredo, L. (1997). O papel do estado para Adam Smith. Belo Horizonte: Universidade Federal de Minas Gerais, Faculdade de Ciências Econômicas, Centro de Planejamento e Desenvolvimento Regional. http://www.cedeplar.ufmg.br/pesquisas/td/TD\%20110. pdf.

Gil, A. C. (2017). Como elaborar projetos de pesquisa (6a ed). Atlas.

Instituto Brasileiro de Geografia e Estatística. (2010). Censo Demográfico. https://censo2010.ibge.gov.br/sinopseporsetores/?nivel=st.

Hobbes, T. (1979). Leviatã ou matéria, forma e poder de um Estado Eclesiástico e Civil (2a ed). Abril Cultural.

Lamarão, M. L. N., \& Maciel, C. A. B. (2006). Mulheres do Bengui: contando histórias de trabalho infantil doméstico. Belém: Gráfica Alves.

Maquiavel, N. (2011). O Príncipe. Hunter Books.

Matos, O. D. (2016). Hobbes e a violência. Sapere Aude, 7(12), 509-514.

Pará. Governo do Estado do Pará. (2011). Lei no 7.584, de 28 de dezembro de 2011. Dispõe sobre a reorganização do Sistema Estadual de Segurança Pública e Defesa Social - SIEDS, e da reestruturação organizacional da Secretaria de Estado de Segurança Pública e Defesa Social - SEGUP, e dá outras providências. http://bancodeleis.alepa.pa.gov.br:8080/lei7584_2011_13314.pdf.

Pará. Governo do Estado do Pará. (2019) Portal da Transparência da Secretaria de Segurança Pública e Defesa Social. http://sistemas.segup.pa.gov.br/transparencia/.

Pará. Governo do Estado do Pará. (2019b). Decreto nº 141, de 10 de Junho 2019. Institui a Política de Inclusão Social e Redução da Violência - “Territórios pela Paz", no Estado do Pará.

Weber, M. (1984). Ciência e política: duas vocações. Cultrix.

Winter, L. M. (2006). A concepção de Estado e de poder político em Maquiavel. Tempo da Ciência, 13(25), 117-128. http://erevista.unioeste.br/index.php/tempodaciencia/article/view/1532.

Vilaça, I. F. T. (2016). Vitimização por Homicídio: Perfil Socioeconômico e Criminal das Vítimas. http://www.ppgsp.propesp.ufpa.br/ARQUIVOS/ teses_e_dissertacoes.

Zaffaroni, E. R. (2017). Em busca das penas perdidas: a perda de legitimidade do sistema penal. (5.ed). Editora Revan.

Zaffaroni, E. R., Batista, N., Alagia, A., \& Slokar, A. (2011). Direito penal brasileiro: teoria geral do direito penal (4.ed). Revan. 